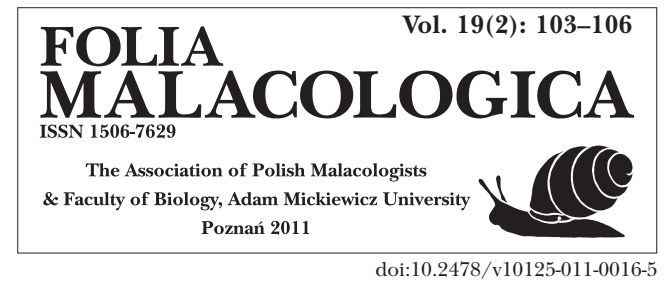

\title{
HAEMOPIS SANGUISUGA (LINNAEUS, 1758) (HIRUDINEA) - THE FIRST OBSERVATION OF A LEECH PREDATION ON TERRESTRIAL GASTROPODS
}

\author{
EVGENII V. SHIKOV
}

Tver State University, Faculty of Biology, Department of Zoology. Prospekt Chaikovskogo 70a, Tver,
Tver Region, 170002, Russia (e-mail: e_v_schik@mail.ru)
Address for correspondence: Shikov E. V., Kalinina 37-21, Lynbertsy, Moscow Region, 140002, Russia

ABSTRACT: The horse leech Haemopis sanguisuga (Linnaeus) was observed to feed on terrestrial gastropods. This is the first observation of a leech predation on terrestrial molluscs.

KEY WORDS: leech, terrestrial gastropods, predation

Many animals, including mammals, birds, reptiles, and insects are known to feed on terrestrial molluscs, but leeches have never been observed to prey on them (BARKER 2004). This paper is based on observations of terrestrial gastropods and horse leech in the central part of the Russian Plain.

In nature, the horse leech Haemopis sanguisuga (Linnaeus, 1758) was observed to prey on young and adult Succinea putris and Trichia hispida in terrestrial environment during rains. In laboratory terraria, the leech was observed to prey on 10 terrestrial snail and slug species representing eight orders and four families, namely, Succineidae: Succinea putris (Linnaeus, 1758), Succinella oblonga (Draparnaud, 1801), Oxyloma elegans (Risso, 1826), O. sarsi (Esmark, 1886); Arionidae: Arion subfuscus (Draparnaud, 1805) s. lat., A. fasciatus (Nilsson, 1822); Bradybaenidae: Fruticicola fruticum (O. F. Müller, 1774) and Helicidae: Trichia hispida (Linnaeus, 1758), Pseudotrichia rubiginosa (A. Schmidt, 1853) and Euomphalia strigella (Draparnaud, 1801)

The horse leech is far from being purely aquatic. On land it feeds on earthworms, copulates and deposits egg cocoons. To protect themselves from drought, the leeches crawl deep into the litter, under stones and pieces of wood, and into the soil (LUKIN 1976). They can be found as far as 30 metres away from water. In some places, even large clusters of up to 16 leech cocoons can be seen under decaying wood. To decrease evaporation from its body surface, the leech makes itself into an elaborate knot (Fig. 1) or, less often, into a spiral. Only during rains it preys on earthworms and, by chance, on molluscs.

Active seeking of molluscs by leeches was not observed. The leech's initial contact with its mollusc prey is most probably accidental. However, having touched a slug or a snail's shell, the leech tries to attach itself firmly to the prey's soft parts at once. The

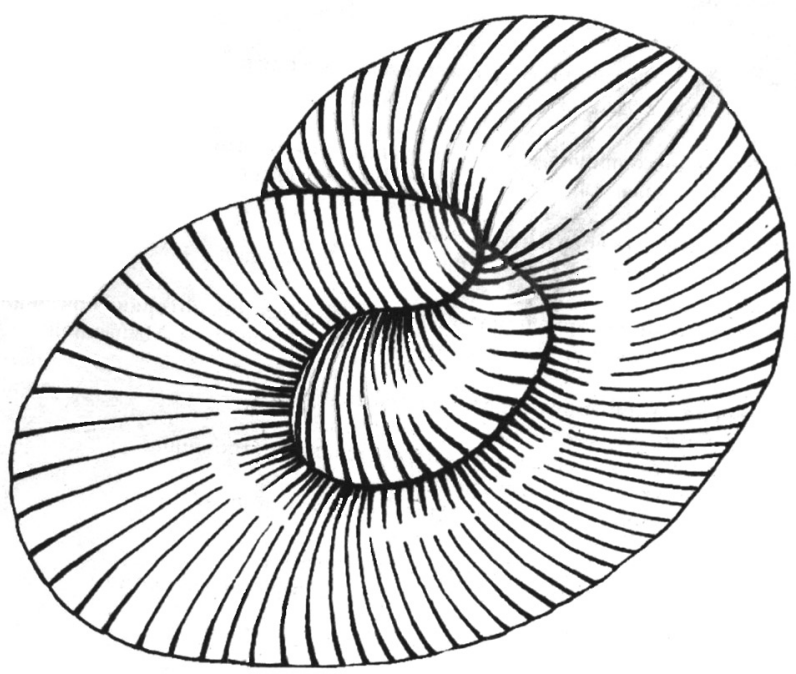

Fig. 1. Horse leech in a knot-like position on land (orig.) 


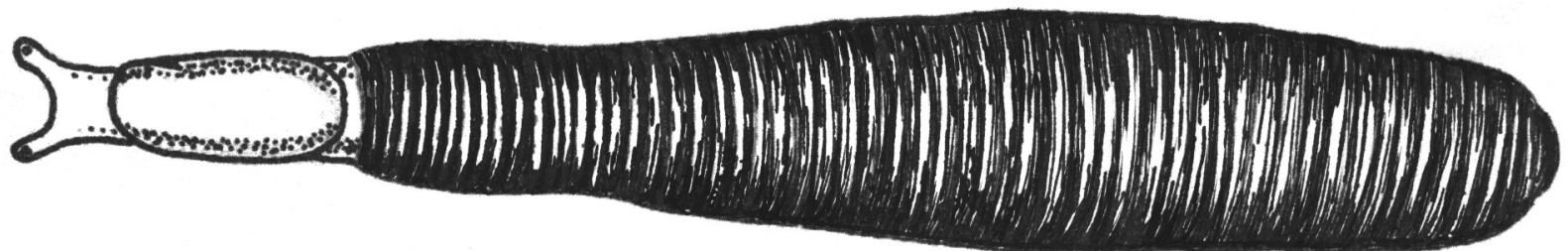

Fig. 2. Horse leech swallowing a slug Arion fasciatus (orig.)

mollusc secretes mucus and tries to crawl away but does not always succeed.

Slugs are swallowed whole. Having attached itself to a slug by suction, the predator slowly crawls onto it swallowing the prey like a snake (Fig. 2). A single slug consumption takes one to several minutes, depending on the prey's size.

Small snails' bodies are also swallowed whole, drawn out of their shells by suction (Figs 3-6). The bodies of large snails are consumed a piece at a time (Figs 7-12). It takes the leech a minute or two to consume a small snail, and several times longer to eat a large one.

The moment a free-crawling leech touches a snail, the predator's behaviour changes abruptly. Its movements become harsh and vigorous. The leech tries to envelop the snail with its body and to fasten to it by suction. The mucus abundantly secreted by the snail
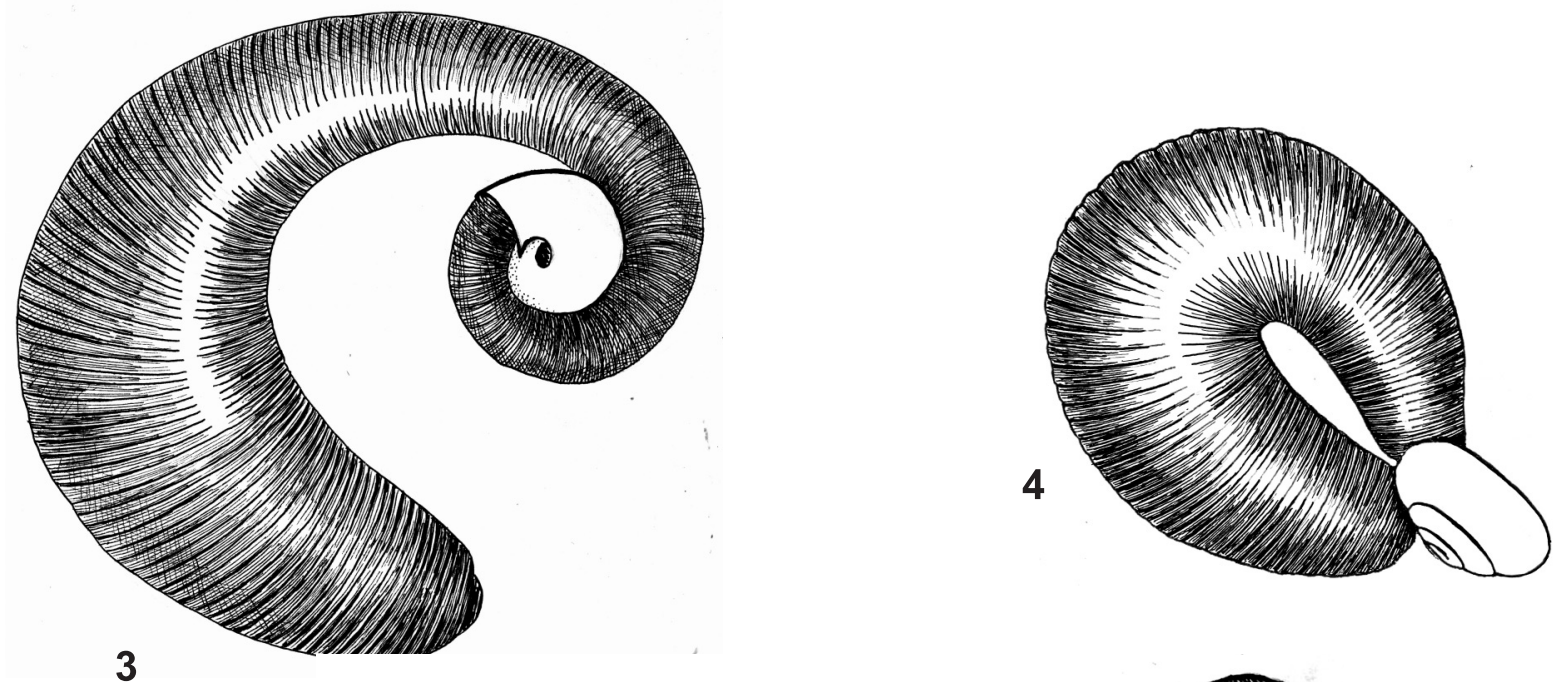

3
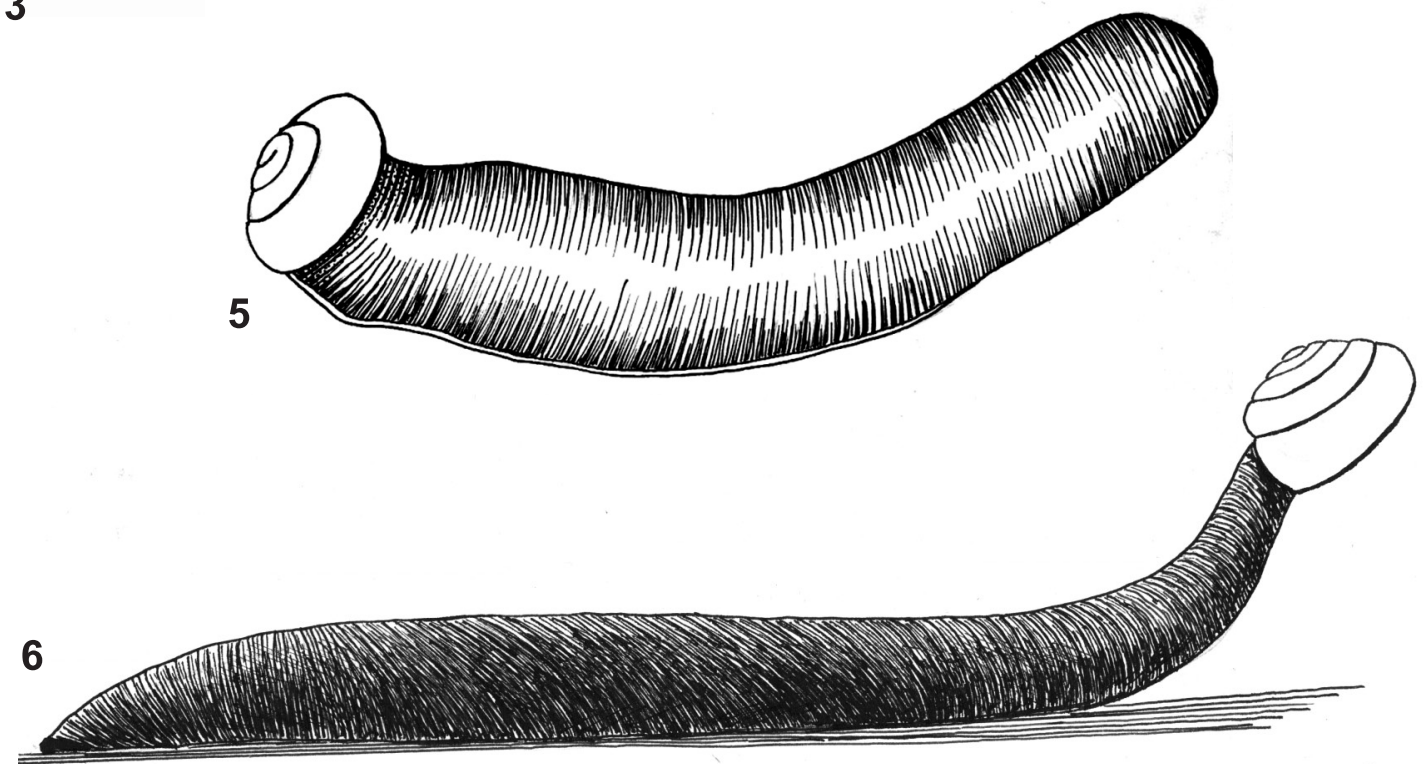

Figs 3-6. Horse leech predating on snails Trichia hispida: 3 - leech entering shell aperture to swallow its prey, 4-6 - different feeding positions (orig.) 

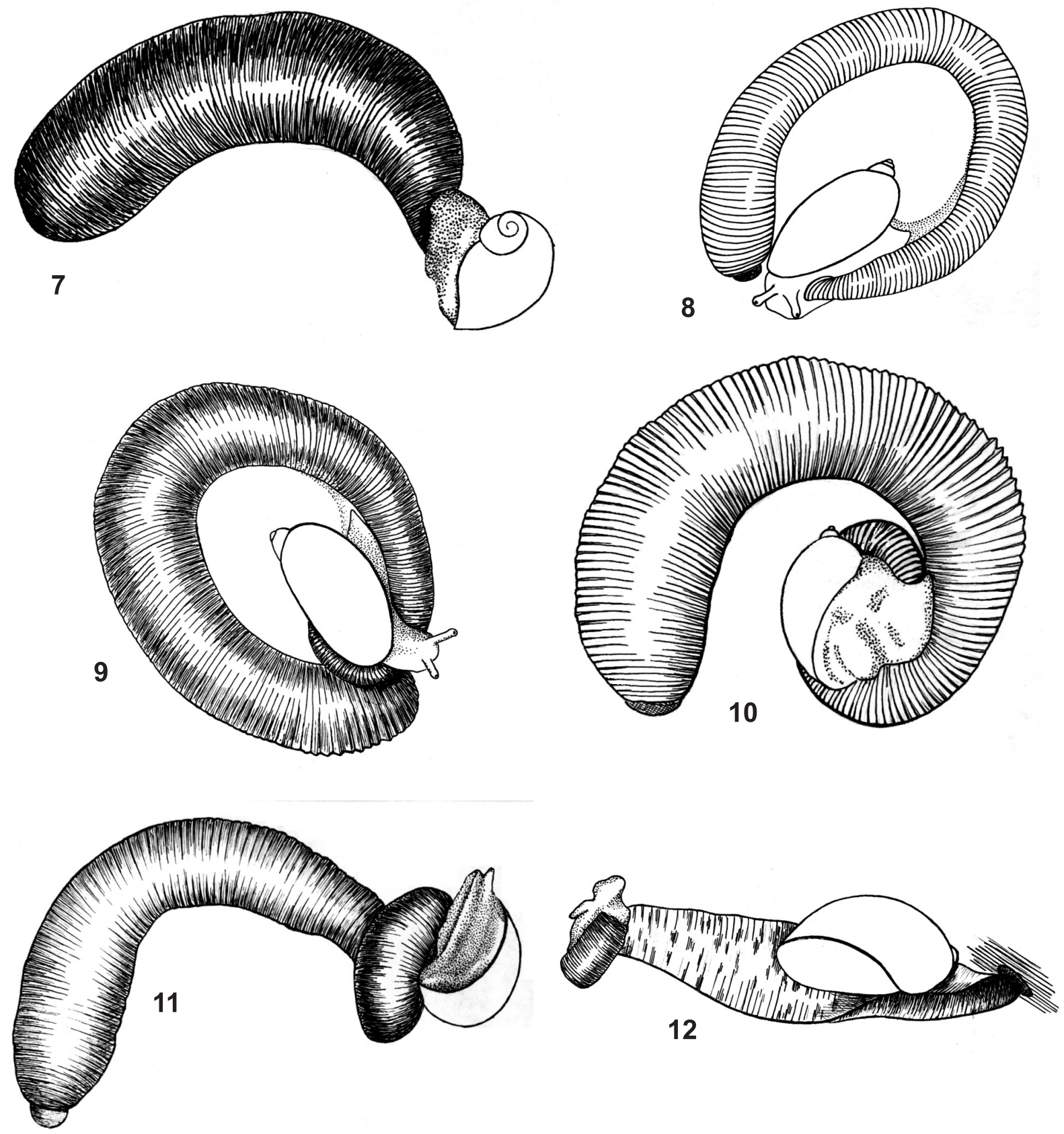

Figs 7-12. Horse leech predating on amber snail Succinea putris: consecutive stages (orig.)

makes this difficult. The snail tries to escape. If it only succeeds to crawl just a few millimetres away from the leech, the predator may simply lose it. In this case, the leech makes convulsive movements with the anterior part of its body, trying to find the prey. If it fails, the mollusc will crawl away. Fast moving amber snails (Succineidae) often manage to escape. Such an escape can happen both at the initial stage of predator to prey contact (Fig. 7) and at the later stage when the leech is enveloping the mollusc's body (Figs 8-12).

Small snails have more difficulties crawling away. The leech usually wraps itself around the mollusc spiral-wise, and the shell often turns upside down. The leech stretches its anterior part into the shell aperture and swallows the snail's body (Fig. 3). When the leech manages to attach itself to a small snail's body fast enough, it may also adopt a different posture during its food consumption (Figs 4-6).

Feeding on terrestrial molluscs is of considerable significance for the horse leech populations living near small ponds and gully springs that dry out in summer. In such places the leeches spend most of their lives on land. They often reside under decaying pieces of wood laying on the soil; gastropods also shelter under such objects, attracted, just like the leeches, by the moisture so well preserved by decaying wood. Feeding on terrestrial slugs and snails helps the horse leech to survive on land. 


\section{REFERENCES}

BARKER G. M. 2004. Natural enemies of terrestrial molluscs.

Received: November 1st, 2010

Landcare Research, Hamilton, New Zealand, CABI PubAccepted: March 3rd, 2011 lishing.

LUKIN E. I. 1976. Piyavki presnykh i solonovatovodnykh vodoyomov. Piyavki. Fauna SSSR 1. Nauka, Leningrad. 